\title{
The left atrial substrate plays a significant role in the development of complex atrial tachycardia in patients with precapillary pulmonary hypertension
}

\author{
Zdenka Fingrova ${ }^{1,2}$, Stepan Havranek ${ }^{1,2^{*}}$ D, David Ambroz ${ }^{1,2}$, Pavel Jansa ${ }^{1,2}$ and Ales Linhart ${ }^{1,2}$
}

\begin{abstract}
Background: Atrial fibrillation (AF) and related atrial tachyarrhythmias (AT), including type I atrial flutter (AFL) are frequently observed in patients with pulmonary hypertension (PH). Their relationship to hemodynamic changes, atrial size, and ventricular function are still not fully verified.

Methods: We retrospectively studied hemodynamic data, echocardiographic findings and arrhythmia incidence in 814 patients with invasively diagnosed precapillary PH (aged $59 \pm 14$ years; $46 \%$ males). Patients with combined or post-capillary PH were excluded.

Results: AF / AT were identified in 225 (28\%) of all the study population. Compared to the subgroup without arrhythmia, patients with AF / AT had elevated right atrial pressure $(11 \pm 5 \mathrm{vs} .9 \pm 5 \mathrm{mmHg})$, wedge pressure (11 \pm 3 vs. $10 \pm 3$ ), a more enlarged right atrium $(50 \pm 12$ vs. $47 \pm 11 \mathrm{~mm}$ ) and an increased left atrial diameter in the parasternal long axis projection, $p<0.05$ for all comparisons. In the multivariate model, the left atrial size, patient age, arterial hypertension, diabetes and type of PH were associated with AF / AT occurrence, $p<0.05$. Patients with type I AFL were more frequently male (39 (80\%) vs. 62 (42\%)), were younger (61 \pm 11 vs. $67 \pm 10$ years), had increased pulmonary artery mean pressure ( $50 \pm 12$ vs. $45 \pm 12 \mathrm{mmHg}$ ), less advanced left atrial dilatation ( $38 \pm 10$ vs. $42 \pm 7 \mathrm{~mm}$ ), and a more enlarged right atrium ( $56 \pm 12$ vs. $48 \pm 11$ ) as compared to subjects with AF or other AT, $p<0.05$.

Conclusions: The evidence of elevated wedge pressure and the enlargement of the left atrium especially in patients with AF suggest a parallel involvement of the left atrial substrate in arrhythmia formation despite invasively confirmed evidence of purely isolated precapillary PH. Substantial differences were noticed between patients with type I AFL and the remaining patients with other arrhythmia types.
\end{abstract}

Keywords: Pulmonary hypertension, Atrial fibrillation, Atrial tachycardia, Atrial flutter

\section{Background}

Pulmonary hypertension $(\mathrm{PH})$ is a pathophysiological disorder characterized by an elevated pulmonary artery mean pressure (PAMP) $\geq 25 \mathrm{mmHg}$ [1]. Hemodynamic parameters evaluated by a right heart catheterization defined the precapillary $\mathrm{PH}$, isolated postcapillary or combined post-

\footnotetext{
* Correspondence: stepan.havranek@|f1.cuni.cz

'2nd Department of Medicine - Department of Cardiovascular Medicine, General University Hospital in Prague, U Nemocnice 2, 12808 Prague, Czech Republic

${ }^{2} 2$ nd Department of Medicine - Department of Cardiovascular Medicine, 1st Faculty of Medicine, Charles University in Prague, U Nemocnice 2, 12808 Praque, Czech Republic
}

(c) The Author(s). 2019 Open Access This article is distributed under the terms of the Creative Commons Attribution 4.0 International License (http//creativecommons.org/licenses/by/4.0/) which permits unrestricted use, distribution, and reproduction in any medium, provided you give appropriate credit to the original author(s) and the source, provide a link to the Creative Commons license, and indicate if changes were made. The Creative Commons Public Domain Dedication waiver (http://creativecommons.org/publicdomain/zero/1.0/) applies to the data made available in this article, unless otherwise stated.

and precapillary $\mathrm{PH}[1,2]$. Despite advances in the management of patients with $\mathrm{PH}$, most treatment strategies relieve symptoms and functional status while evidence of prognostic improvements and survival is limited [1].

Supraventricular tachycardias has been frequently (range of cumulative incidence 10-25\%) observed in patients with idiopathic pulmonary arterial hypertension (PAH) [3], in all types of $\mathrm{PH}$ [4-6], inoperable chronic thromboembolic pulmonary hypertension (CTEPH) $[4,6]$ or Eisenmenger syndrome [7]. Atrial tachyarrhythmias leads to clinical deterioration and may be associated with an increased risk of death $[3,4,6,8]$. Out of all types of supraventricular 
tachycardias in the $\mathrm{PH}$ population, atrial fibrillation (AF) and related atrial tachyarrhythmias (AT), including type I atrial flutter (AFL) are the most frequently observed [3-7].

It is known that there is a relationship between right atrium (RA) enlargement in patients with $\mathrm{PH}$ and the increased prevalence of supraventricular arrhythmia [9], however, limited data is available on the arrhythmogenic substrate for complex ATs including AF in patients with precapillary $\mathrm{PH}$. Although some studies in patients with $\mathrm{PH}$ or respiratory disease suggested that substrate for AF / AT could be predominantly situated in the RA [10-13], the role of the arrhythmogenic substrate in the left atrium (LA) and left atrial pressure in patients with precapillary $\mathrm{PH}$ is generally unknown.

In order to further evaluate the role of the left and right atrial substrate in the development of AF / AT in patients with precapillary $\mathrm{PH}$, we conducted a retrospective analysis of records focused on left and right cardiac morphology and haemodynamics in patients with precapillary $\mathrm{PH}$ and $\mathrm{AF} / \mathrm{AT}$.

\section{Methods}

Consecutive unselected patients, who were diagnosed and treated for $\mathrm{PH}$ at a single centre between 2003 and 2017, were enrolled in the retrospective analysis. Patient data was retrieved from a dedicated registry. The study was performed according to good clinical practice and in compliance with the Helsinki declaration. An individual written consent was obtained from each patient. The study was approved by the local Ethics committee.

All patients have undergone a complete routine baseline in-hospital work-up according to contemporary standards $[1,10,11]$ including a medical history assessment, concomitant diseases, clinical severity, functional capacity, complete laboratory tests, echocardiography, and other noninvasive and invasive methods. All included patients underwent a right heart catheterization demonstrating $\mathrm{PH}$ with a pulmonary artery mean pressure (PAMP) $\geq 25$ $\mathrm{mmHg}$. Only patients with precapillary $\mathrm{PH}$ with a pulmonary artery wedge pressure (PAWP) $\leq 15 \mathrm{mmHg}$ were included in the current analysis. The classification of $\mathrm{PH}$ and patient management was done according to current European Society of Cardiology guidelines [2]. Patients with $\mathrm{PAH}, \mathrm{PH}$ due to lung diseases and/or hypoxia, CTEPH and a group of $\mathrm{PH}$ with unclear and/or multifactorial mechanisms were enrolled in the study.

For patients with CTEPH, assessment of operability included perfusion scintigraphy and pulmonary angiography and when eligible, pulmonary endarterectomy (PEA) was indicated.

All patients were regularly seen at 1 to 6 monthly intervals, or whenever clinically indicated, in an outpatient clinic. Standard 12-lead ECG were obtained as part of a regular follow-up program.
Prevalent AF / AT (common, type I AFL included) was defined as the presence of arrhythmia on 12-lead surface ECGs, 24-h ECG monitors and / or during invasive electrophysiology testing and / or as indicated by a diagnosis found in the medical records, hospitalization or ambulatory databases. The diagnosis of AF / AT was confirmed by an experienced cardiologist.

Based on clinical experiences and referred guidelines, rhythm control, i.e. the restoration of the sinus rhythm was usually attempted in all patients with symptomatic or clinically significant tachycardia which was not previously classified as permanent, irrespective of the heart rate and underlying conditions. Patients with previously documented, known paroxysmal or persistent AF or other AT than type I AFL were treated with electrical cardioversion, if the sinus rhythm was not restored spontaneously or after initial antiarrhythmic therapy or in cases of heart failure symptoms. When symptomatic recurrent AF / AT was manifested, a catheter ablation (CA) was scheduled. In cases of type I AFL, the primary strategy was to restore the sinus rhythm with an early CA and whatever seemed appropriate in the given clinical context. Electro-anatomical mapping (CARTO 3, Biosense-Webster Inc., Diamond Bar, CA, USA) was used in several cases when a more complex arrhythmia or arrhythmogenic substrate was predicted. In that case, manual catheter navigation was used for reconstruction of the atrial endocardial surface. Uniformly distributed mapping points were acquired at sites with stable endocardial contact. Special attention was paid to make sure mapping points were not included behind the pulmonary vein ostia. The orifice and proximal part of LA / RA appendage was always mapped. Precise delineation of the mitral annulus was performed in all cases. Intracardiac echocardiography was used to visualize and tag critical structures. 3D dense bipolar voltage maps of the atria were built ( $>100$ points). Low-voltage regions were defined as bipolar voltage $<0.1 \mathrm{mV}$. The size of low-voltage areas was rated as a proportion of the surface area with reduced bipolar voltages from the whole atrial surface (mitral and tricuspidal annuli were excluded). Atrial volume was assessed using a built-in computation function of the Biosense system.

\section{Statistical analysis}

Continuous variables were expressed as means with standard deviations after testing for normality (Shapiro-Wilk's test) and compared with the 2-tailed t-test for independent samples or advanced ANOVA tests. Categorical variables were expressed as percentages and compared with the $\mathrm{X}^{2}$-test or Kruskal-Wallis test when appropriate. Multivariate analysis was used to identify independent predictors of mortality. $P$-value $<0.05$ was considered significant. All analyses were performed using the STATISTICA vers.12 software (Statsoft, Inc., Tulsa, USA). 


\section{Results}

A total of 814 patients (aged $59 \pm 14$ years; $46 \%$ males) were analysed. Baseline characteristics of the total population and subgroups are shown in Table 1. Arrhythmia was documented in 225 (28\%) of the subjects. Patients with a history of AF / AT were older, had more frequently arterial hypertension, diabetes mellitus and were treated with a specific therapy. Out of all patients with arrhythmia, AF was manifested in 149 (66\%) and AT in 76 (34\%) subjects, respectively. Type I AFL was diagnosed in 49 patients (64\% of all subjects with AT). An excessive prevalence of AF / AT was noticed among patients with CTEPH (AF: 49 (55\%), AFL: 28 (31\%), other AT: $11(12 \%)$ ), and more specifically when patients were treated by PEA (AF: 25 (64\%), AFL: 20 (40\%), other AT: 6 (12\%)).

Patients with a history of AF / AT had significantly larger LA diameters, end-diastolic left ventricular (LV) diameter and RA short diameter estimated with 2D echocardiography. In the same group, the PAWP and RA pressure (RAP) were also elevated as compared to patients without arrhythmias, Table 2 and Fig. 1. In contrast, there was no significant difference in right ventricular (RV) diameters, tricuspid annular plane systolic excursion (TAPSE) and LV ejection fraction when patients with and without AF / AT were compared. For more details see Table 2 . When comparing patients who already had existing arrhythmia at the time of the $\mathrm{PH}$ diagnosis of $\mathrm{PH}$ with those with new-onset of AF / AT during a follow-up, no significant difference in the LA diameter was recognized ( $46 \pm 8$ vs. $44 \pm 8 \mathrm{~mm} ; p=$ 0.3). Patients with paroxysmal forms and persistent /
Table 2 Echocardiographical and heamodynamical data

\begin{tabular}{llll}
\hline & Arrhythmia & Arrhythmia & $p$ \\
& YES & NO & \\
& $(\mathrm{n}=225)$ & $(\mathrm{n}=589)$ & \\
\hline LA diameter / PLAX (mm) & $44 \pm 8$ & $40 \pm 10$ & $<0.001$ \\
LA long / A4C (mm) & $55 \pm 9$ & $50 \pm 8$ & $<0.0001$ \\
LA short / A4C (mm) & $40 \pm 8$ & $36 \pm 8$ & $<0.0001$ \\
RA short / A4C (mm) & $50 \pm 12$ & $47 \pm 11$ & $<0.01$ \\
RV short / A4C (mm) & $46 \pm 10$ & $45 \pm 10$ & NS \\
TAPSE (mm) & $18 \pm 5$ & $18 \pm 5$ & NS \\
LV enddiastolic diameter (mm) & $47 \pm 8$ & $44 \pm 8$ & $<0.01$ \\
LV EF (\%) & $62 \pm 9$ & $63 \pm 8$ & NS \\
PAMP (mm Hg) & $47 \pm 13$ & $49 \pm 16$ & NS \\
RAP (mm Hg) & $10.5 \pm 5.1$ & $9.3 \pm 5.1$ & $<0.01$ \\
PAWP (mm Hg) & $11.4 \pm 2.8$ & $10.2 \pm 3.1$ & $<0.01$ \\
\hline
\end{tabular}

Legend: Values are expressed as mean \pm SD. LA Left atrium, RA Right atrium, $R V$ Right ventricle, $L V$ Left ventricle, TAPSE Tricuspid annular plane systolic excursion, EF Ejection fraction, PAMP Pulmonary artery mean pressure, RAP Right atrial pressure, PAWP Pulmonary artery wedge pressure, PLAX Parasternal long axis projection, $A 4 C$ Apical four chamber projection

permanent forms of arrhythmia had LA diameters without any variance ( $46 \pm 7$ vs. $48 \pm 8 \mathrm{~mm} ; p=0.1$ ).

In a multivariate model of the LA diameter in a parasternal long axis projection; age, arterial hypertension, diabetes and type of $\mathrm{PH}$ were associated with the occurrence of AF / AT (Table 3).

Out of all patients with arrhythmia, $49(22 \%)$ subjects manifested type I AFL. When compared to patients with

Table 1 Baseline clinical and demographical data

\begin{tabular}{|c|c|c|c|c|}
\hline & Total $(n=814)$ & $\begin{array}{l}\text { Arrhythmia YES } \\
(n=225)\end{array}$ & $\begin{array}{l}\text { Arrhythmia } \mathrm{NO} \\
(n=589)\end{array}$ & $p$ \\
\hline Age (years) & $59 \pm 14$ & $65 \pm 11$ & $57 \pm 15$ & $<0.001$ \\
\hline Males & $378(46 \%)$ & $113(50 \%)$ & $265(45 \%)$ & NS \\
\hline Group $1 \mathrm{PH}: \mathrm{PAH}$ & $334(41 \%)$ & 87 (39\%) & $247(41 \%)$ & NS \\
\hline Group 3 PH: Lung diseases & $140(17 \%)$ & $23(10 \%)$ & $117(20 \%)$ & 0.0007 \\
\hline Group 4 PH: CTEPH & 303 (37\%) & 106 (47\%) & 197 (33\%) & 0.0002 \\
\hline Group 5 PH: Other types of PH & $37(5 \%)$ & $9(4 \%)$ & $28(5 \%)$ & NS \\
\hline Arterial hypertension & $470(58 \%)$ & $160(71 \%)$ & $310(53 \%)$ & $<0.0001$ \\
\hline Diabetes mellitus & $204(25 \%)$ & $74(33 \%)$ & $130(22 \%)$ & 0.03 \\
\hline Coronary artery disease & $168(21 \%)$ & $49(22 \%)$ & $119(20 \%)$ & NS \\
\hline $\begin{array}{l}\text { Chronic obstructive pulmonary } \\
\text { disease / obstructive sleep apnea }\end{array}$ & $195(23 \%) / 49$ (6\%) & $62(28 \%) / 10(4 \%)$ & $133(22 \%)$ / 39 (7\%) & NS \\
\hline Specific therapy & $416(51 \%)$ & 109 (48\%) & 307 (52\%) & $<0.01$ \\
\hline PEA in CTEPH & $173(21 \%)$ & $68(30 \%)$ & 105 (18\%) & 0.0002 \\
\hline NYHA & $2.69 \pm 0.79$ & $2.66 \pm 0.81$ & $2.71 \pm 0.78$ & NS \\
\hline 6-min walking test (m) & $341 \pm 129$ & $329 \pm 127$ & $346 \pm 129$ & NS \\
\hline Mortality & 379 & $140(49 \%)$ & $320(48 \%)$ & NS \\
\hline
\end{tabular}

Legend: Values are expressed as Mean \pm SD or $\mathrm{n}(\%)$. PH Pulmonary hypertension, PAH Pulmonary arterial hypertension, CTEPH Chronic thrombembolic pulmonary hypertension, PEA Pulmonary endarterectomy 


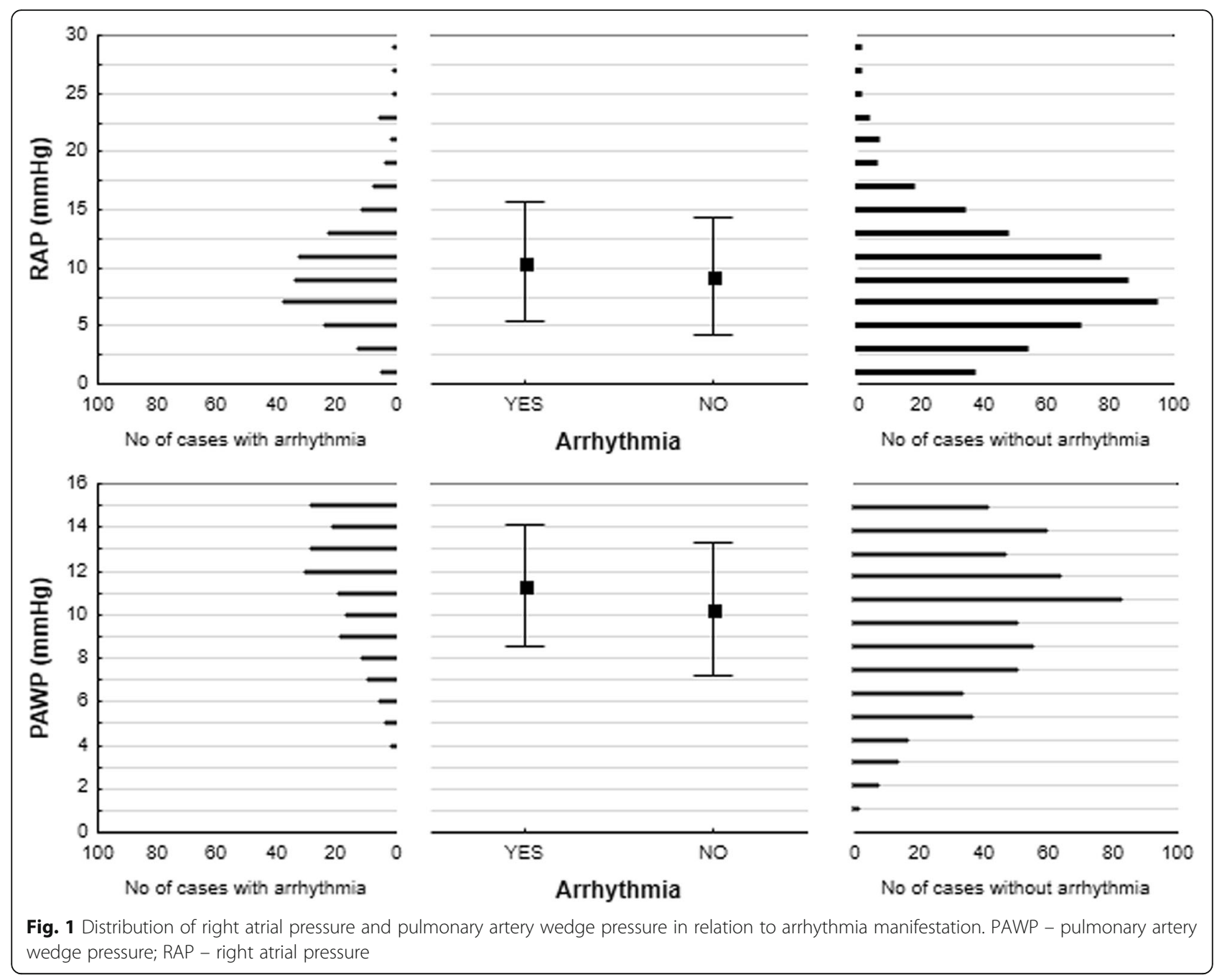

type I AFL, subjects with AF or other AT were more frequently female, had more prevalent diabetes, were older, manifested more reduced 6-min walking test distance, lower PAMP values, advanced LA dilatation, smaller RA and RV diameters and better TAPSE. More details are shown in Fig. 2. In addition, patients with AFL manifested higher values of RAP then patients with AF (12 \pm 6 vs. $9 \pm 5 \mathrm{mmHg} ; p=0.01$ ). After excluding AFL patients, the differences in RAP between AF patients and patients without arrhythmia are nonsignificant $(9 \pm 5$ vs. $10 \pm 5 \mathrm{mmHg} ; p=0.1$ ). The PAWP values were comparable between AFL and AF patients $(11 \pm 3$ vs. $12 \pm 3$ $\mathrm{mmHg}, p=0.15)$.

Out of 45 patients treated with CA, electroanatomical mapping was used in 11 (24\%) cases. Overall 9 patients (20\%) manifested common AFL as a clinical diagnosis. One patient had both AFL and a nonspecified AT. One patient manifested AF and a different AT. And 1 patient had AF. In all patients an electroanatomical map of RA was performed. In three cases
Table 3 Multivariate analysis. Prediction of arrhythmia occurrence

\begin{tabular}{lll}
\hline Parameter & $F$ & $p$ \\
\hline Age (years) & 5.1 & 0.02 \\
Arterial hypertension & 6.0 & 0.015 \\
Diabetes mellitus & 7.1 & 0.01 \\
Occurrence of PAH & 5.1 & 0.0001 \\
Specific therapy & 3.0 & NS \\
LA diameter in PLAX (mm) & 5.1 & 0.02 \\
RA diameter in A4C (mm) & 0.8 & NS \\
LV enddiastolic diameter (mm) & 2.5 & NS \\
RA pressure (mmHg) & 0.02 & NS \\
PAWP (mmHg) & 0.1 & NS
\end{tabular}

Legend: Significant variables from Tables 1 and 2 were included. $P H$ Pulmonary hypertension, $L A$ Left atrium, RA Right atrium, $L V$ Left ventricle, PAWP Pulmonary artery wedge pressure, PLAX Parasternal long axis projection, $A 4 C$ Apical four chamber projection 

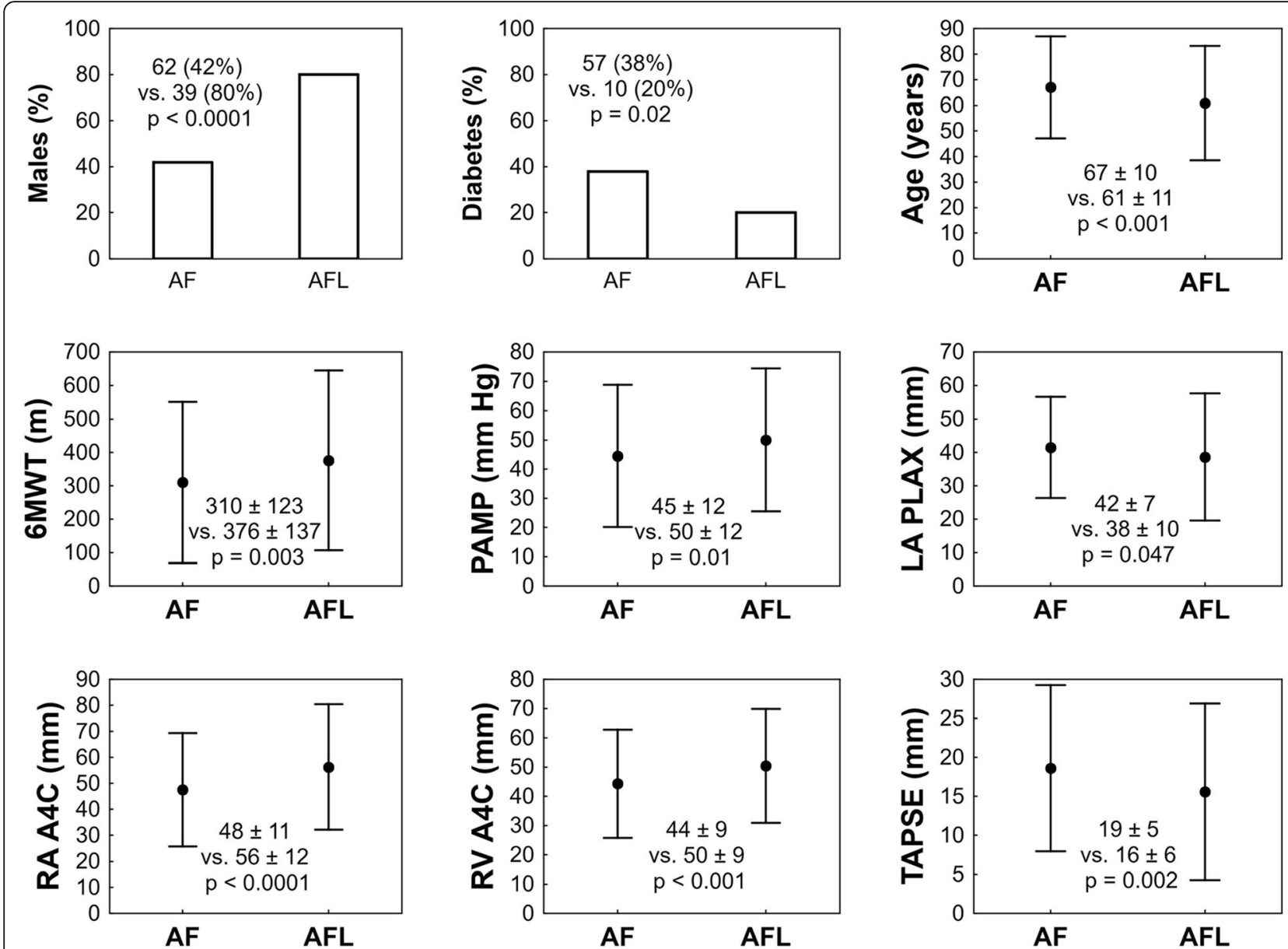

Fig. 2 Clinical, demographical, haemodynamic and echocardiographic data in patients with atrial fibrillation and flutter. Values are expressed as mean \pm standard deviation or as $\mathrm{n}(\%)$. AF - atrial fibrillation; AFL - atrial flutter; $6 \mathrm{MWT}$ - six-minute walking test; PAMP - pulmonary arterial mean pressure; PAWP - pulmonary arterial wedge pressure; LA - left atrium; RA - right atrium; RV - right ventricle; TAPSE - tricuspid annular plane systolic excursion

left atrial mapping was performed as well. More details are listed in Table 4 and Fig. 3.

\section{Discussion}

The major finding of our study is that in addition to right atrial dilatation, the left atrial substrate is very likely to be involved in the pathogenesis of AF / AT in patients with invasively confirmed isolated precapillary $\mathrm{PH}$. Our data indicates that a different arrhythmogenic mechanism is probably involved in typical right atrial arrhythmia such as type I AFL as compared to AF or other types of AT.

\section{Pathophysiological mechanism of AF / AT in precapillary \\ $\mathrm{PH}$}

Apart from the clear mechanisms of supraventricular tachycardias (i.e. atrio-ventricular nodal reentry tachycardia or atrio-ventricular reentry tachycardia), an arrhythmogenic substrate for complex atrial arrhythmias including AF or AT in $\mathrm{PH}$ patients remains unclear. However, there is emerging evidence indicating a right sided substrate for complex atrial arrhythmia: $\mathrm{PH}$ leads to an increased afterload of the RV, resulting in RV hypertrophy and dilatation as well as upstream enlargement of the RA [14]. Long-standing PH is frequently associated with decreased conduction and tissue voltage in some cases with regions of "electrical silence" in both the RA and RV [15]. In addition, modulations of the autonomic system may trigger and perpetuate related arrhythmia $[16,17]$.

The mechanisms of arrhythmia have been suggested as most likely different and more similar to proarrhythmogenic substrate in left heart disease when a post-capillary component is present [8]. In cases of left heart disease, elevated end-diastolic left ventricular pressure is a well-known mechanism leading to LA structural remodeling with proarrhythmogenic effect. Left atrial remodeling, particularly LA dilatation 
Table 4 Pilot data of LA / RA morphology in some patients after catheter ablation with the use of electro-anatomical mapping

\begin{tabular}{|c|c|c|c|c|c|c|c|c|c|c|c|c|}
\hline \# Case & Gender & $\begin{array}{l}\text { Age } \\
\text { (years) }\end{array}$ & $\begin{array}{l}\text { Type } \\
\text { of PH }\end{array}$ & $\begin{array}{l}\text { Type of } \\
\text { arrhythmia }\end{array}$ & $\begin{array}{l}\text { RAP } \\
(\mathrm{mm} \mathrm{Hg})\end{array}$ & $\begin{array}{l}\text { RA } \\
\text { short (mm) }\end{array}$ & $\begin{array}{l}\text { PAWP } \\
(\mathrm{mm} \mathrm{Hg})\end{array}$ & $\begin{array}{l}\mathrm{LA} \vee P L A X \\
(\mathrm{~mm}) / \mathrm{LAVi} \\
\left(\mathrm{ml} / \mathrm{m}^{2}\right)\end{array}$ & $\begin{array}{l}\text { RA CARTO } \\
\text { volume (ml) }\end{array}$ & $\begin{array}{l}\text { RA surface / } \\
\text { low voltage } \\
\text { surface }\left(\mathrm{cm}^{2}\right)\end{array}$ & $\begin{array}{l}\text { LACARTO } \\
\text { volume } \\
(\mathrm{ml})\end{array}$ & $\begin{array}{l}\text { LA surface / } \\
\text { low voltage } \\
\text { surface } \\
\left(\mathrm{cm}^{2}\right)\end{array}$ \\
\hline 1 & $M$ & 73 & CTEPH & AFL & 6 & 63 & 8 & $55 / 41$ & 180 & $196 / 1$ & - & - \\
\hline 2 & M & 81 & CTEPH & AFL & 9 & 40 & 12 & $54 / 41$ & 151 & $166 / 20$ & - & - \\
\hline 3 & $\mathrm{~F}$ & 72 & CTEPH & AFL & 8 & 45 & 13 & $43 / 44$ & 183 & $175 / 1$ & - & - \\
\hline 4 & M & 75 & Hypoxic & AFL & 8 & 54 & 3 & $41 / 22$ & 242 & $228 / 31$ & - & - \\
\hline 5 & $\mathrm{~F}$ & 81 & CTEPH & $\mathrm{AF} / \mathrm{AT}$ & 6 & 38 & 13 & $38 / 30$ & 191 & $198 / 9$ & - & - \\
\hline 6 & $F$ & 74 & Hypoxic & AFL & 9 & 66 & 11 & $56 / 47$ & 184 & $198 / 38$ & - & - \\
\hline 7 & M & 59 & PAH & AFL & 20 & 77 & 9 & $52 / 30$ & 276 & $267 / 2$ & - & - \\
\hline 8 & M & 74 & CTEPH & AFL & 19 & 51 & 12 & $53 / 35$ & 206 & $202 / 5$ & 180 & $182 / 2$ \\
\hline 9 & M & 61 & CTEPH & AFL & 14 & 56 & 10 & $40 / 52$ & 217 & $228 / 33$ & - & - \\
\hline 10 & M & 46 & $\mathrm{PAH}$ & AFL / AT & 13 & 77 & 6 & $40 / 12$ & 395 & $296 / 26$ & 90 & $123 / 0$ \\
\hline 11 & M & 87 & CTEPH & AF & 6 & 64 & 14 & $56 / 73$ & 324 & 174 / 16 & 173 & 169 / 18 \\
\hline
\end{tabular}

Legend: $M$ Male, $F$ Female, RAP Right atrial pressure, RA Right atrium, PAWP Pulmonary artery wedge pressure, LA Left atrium, PLAX Parasternal long axis projection, LAVi Indexed left atrial volume, CTEPH Chronic thromboembolic pulmonary hypertension, AFL Atrial flutter type I, AF Atrial fibrillation, AT Atrial tachycardia, PAH Pulmonary arterial hypertension

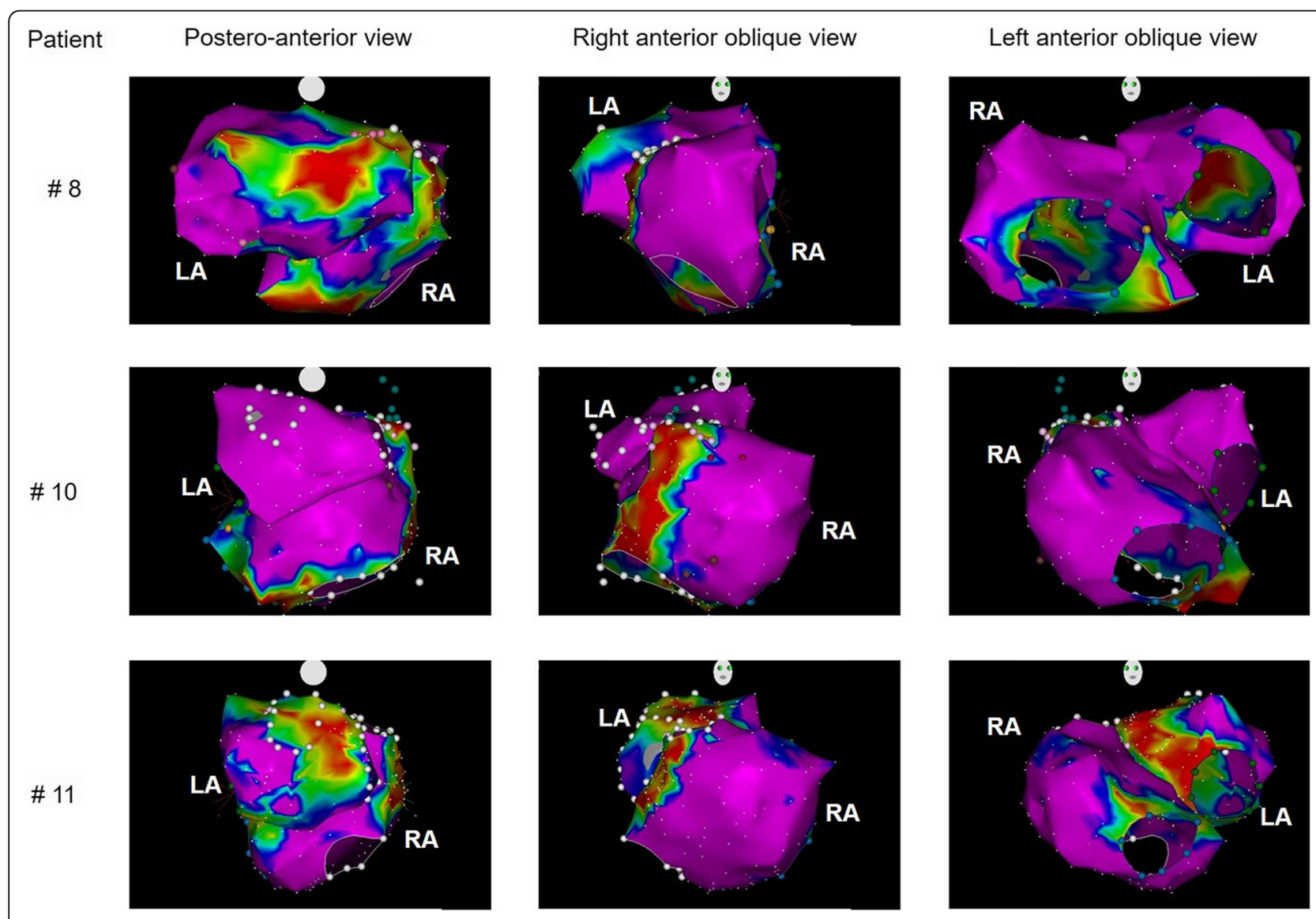

Fig. 3 An example of RA and LA arrhythmogenic substrate. Example of 3D electro-anatomical bipolar voltage maps of both right and left atrium (see Table 4 for more individual details). Red colour represents areas with reduced bipolar voltage $(<0.1 \mathrm{mV})$. LA - left atrium; RA - right atrium 
is a well-documented risk factor for the development of $\operatorname{AF}[18,19]$.

Despite the inclusion of only precapillary $\mathrm{PH}$ patients, increased LA diameters, LV end-diastolic diameter and higher PAWP in combination with increased RA size and elevated RAP were detected in patients with arrhythmia in our study. In addition the only change in the LA diameter in PLAX was associated with an occurrence of AF / AT in a multivariate analysis, and not with right atrial parameters. We, therefore, speculate that the left atrial substrate plays a role in arrhythmogenesis of more complex atrial tachycardias even in the presence of purely precapillary $\mathrm{PH}$.

One factor possibly explaining the involvement of the left heart in the pathogenesis of AF / AT in PAH patients may be due to the definition of precapillary $\mathrm{PH}$ itself. PAH diagnosis is based uniquely on resting invasive pulmonary pressure measurements. In addition, the PAWP limit is set relatively high, above the limits of presumed true physiological values. This may lead to a diagnosis of purely precapillary $\mathrm{PAH}$ in a group of patients, in whom pulmonary hypertension is actually a combined one (combined postcapillary and precapillary $\mathrm{PH}$ ). It has been repeatedly shown $[20,21]$ that a fluid challenge or exercise can unmask a postcapillary component in a large number of patients. This hypothesis would be supported by the fact, that in our study diabetes and arterial hypertension - frequent risk factors for left heart involvement with diastolic dysfunction - predicted the development of arrhythmias. As suggested by Opitz [22], these cases represent a borderline category of patients with "atypical idiopathic PAH" in whom left heart involvement remains silent under resting conditions. Finally, in borderline PAWP cases, the measurement method of PAWP may lead to an underestimation (using a digitized mean value) or overestimation (using end-expiratory values) of PAWP [23]. Our data supports the hypothesis of the participation of the truly elevated LA pressure on the development of LA substrate and its arrhythmogenity. The distribution of PAWP had negative skewness and a significant proportion of AT / AF patients contained values close to the threshold limit.

On the other hand, the high burden paroxysmal, persistent or permanent arrhythmia may be a cause of LA remodeling itself $[18,19]$. Decreased atrial contraction, atrio-ventricular asynchrony, and a rapid heart rate with a reduction of diastolic filling are potential factors of left atrial remodeling. Moreover, it has been found that AF itself causes electrophysiological changes of the atrial myocardium which explains the progressive character of arrhythmia [24]. Since the LA diameter has not been significantly different according to the type of arrhythmia and is not dependent on time of onset of AT / AF, the impact of pure arrhythmia's burden to atrial remodeling is not a simple explanation of LA enlargement in our study population. However, aging and external stressors such as arterial hypertension or diabetes, associated in our study with the presence of AF / AT were identified in our data. All those conditions are also well known factors influencing atrial electrophysiological and structural remodeling of the LA, which can be associated with the initiation of $\mathrm{AF}$ in the general population $[25,26]$ and also in the $\mathrm{PH}$ population [15]. These facts are well in line with our data and warrant a hypothesis of the existence of some left sided proarrhythmogenic substrate among patients with arrhythmia and precapillary $\mathrm{PH}$.

Incidental findings of reduced bipolar voltages on some electro-anatomical maps of the LA support the hypothesis of the cooperation of both the left and right atrium in the pathogenesis of AF / AT in a given population. LA scarring can be detected by late enhancement magnetic resonance imaging and can be correlated well with reduced electrogram amplitudes as recorded by endocardial voltage maps [27, 28]. Atrial structural remodeling involving atrial fibrosis and scarring is a well-recognized factor in AF pathogenesis.

\section{Comparison of patients with AF and AFL}

Our data shows substantial differences between patients with typical right sided arrhythmia i.e. type I AFL and AF in clinical, echocardiographic and hemodynamic variables. Patients with AFL were more likely to be male, demonstrated an enlarged RA and RV, reduced RV systolic function and higher PAMP and RAP values. These cases are probably representing the consequence of true typical IPAH. Structural remodeling of the RA relating to longstanding $\mathrm{PH}$ with right ventricular overload and increased $\mathrm{RV}$ filling pressures would be prone to provoke reentry arrhythmia in the dilated RA $[13,14,29]$. Our data is in line with this observation, higher levels of RAP in patients with arrhythmia is given by higher RAP values in patient with AFL. After the exclusion of those patient with AFL, RAP is comparable between the rest of the arrhythmia group and patients without any rhythm disorder. We speculate, that the reduction of the 6-min walking test distance in the AFL subgroup is more likely a result from more advanced RA and RV dysfunction.

\section{Prevalence of arrhythmia in precapillary $\mathrm{PH}$}

The prevalence of AF / AT in our PH population was higher than in a majority of published reports. Most retrospective and prospective studies have reported a cumulative incidence of supraventricular arrhythmia ranging from 10 to $25 \%$ in patients with $\mathrm{PAH}$ or inoperable CTEPH $[5,6,8]$. Only one retrospective study showed a similar (29\%) cumulative incidence of arrhythmias comparable to our data in a subgroup of patients with $\mathrm{PAH}$ [8]. The higher prevalence of arrhythmia in the overall $\mathrm{PH}$ groups in our cohort is more likely given to the inclusion criteria and systematic long-lasting follow-ups 
for patients. According to our protocol, all patients with a detected AF / AT in their entire personal history were taken into account. Thus, our data refers to a cumulative prevalence of cases as a baseline and new case incidences together.

We detected an excessive proportion of CTEPH patients in the arrhythmia group. This prevalence is most likely given, by the high prevalence of type I AFL. An excessive proportion of AFL was detected in the CTEPH subgroup treated with PEA. Two more explanations for the increased prevalence of AFL in that group may be offered. Both advanced RA scarring resulting from RA cannulation or incision and spontaneous RA remodeling might be a plausible explanation for right sided macroreentrant tachycardia such as AFL.

\section{Limitations}

We must admit several limitations of our study of which the most limiting is its retrospective design. Despite a meticulous and systematic follow-up, some arrhythmias may have been missed. Our data was based on standard electrocardiograms and carefully gathered patient histories. However, due to a lack of other means of rhythm monitoring, it is likely that some self-terminating, clinically silent AF episodes might have been missed. Moreover, our hemodynamic investigation was based on a standard resting right heart catheterization which is unable to detect cases of atypical forms of PAH in whom PCWP may steeply rise during the exertion of a fluid challenge, unmasking the postcapillary component.

\section{Conclusion}

Our study supports the role of the LA substrate in arrhythmogenesis of complex atrial arrhythmias, especially $\mathrm{AF}$, despite the evidence of pure precapillary $\mathrm{PH}$ as diagnosed by right heart catheterization at rest. Conversely, our data suggest that the mechanism of type I AFL is more likely dependent on right atrial remodeling. An existence of both left and right atrial substrate was incidentally detected in some cases ablated with use of electro-anatomical mapping.

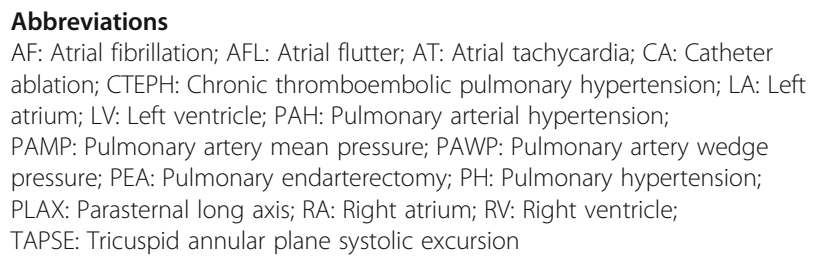

\section{Acknowledgments}

We would like to thank Mrs. Hana Fingrova and Valerie Reeves for language correction.

\section{Authors' contributions}

ZF and SH participated in data collection and analysis, and drafted the manuscript, DA and PJ participated in data collection and analysis, AL conceived the study design, participated in data collection and analysis, performed statistical analysis, and critically revised the manuscript for important intellectual content. All authors have read and approved the final manuscript.

\section{Funding}

The study was supported by Ministry of Health of the Czech Republic, grant nr. NV18-02-00027 and Progres Q38/LF1. None of the funding bodies had any impact on the design of the study and collection, analysis, and interpretation of data and the writing the manuscript.

\section{Availability of data and materials \\ All relevant data is in the manuscript. The datasets used are available from the corresponding author upon a reasonable request.}

\section{Ethics approval and consent to participate}

The study was performed according to good clinical practice and in compliance with the Helsinki declaration. An individual written consent was obtained from each patient. The study was approved by the local Ethics committee (Ethics Committee in General University Hospital in Prague) - No. 1121/16-S-IV.

\section{Consent for publication}

Not applicable.

\section{Competing interests}

The authors declare that they have no competing interests.

Received: 5 March 2019 Accepted: 25 June 2019

Published online: 28 June 2019

\section{References}

1. Galie N, Humbert M, Vachiery JL, Gibbs S, Lang I, Torbicki A, et al. 2015 ESC/ ERS guidelines for the diagnosis and treatment of pulmonary hypertension: the joint task force for the diagnosis and treatment of pulmonary hypertension of the European Society of Cardiology (ESC) and the European Respiratory Society (ERS): endorsed by: Association for European Paediatric and Congenital Cardiology (AEPC), International Society for Heart and Lung Transplantation (ISHLT). Eur Heart J. 2016;37(1):67-119.

2. Simonneau G, Galie N, Rubin LJ, Langleben D, Seeger W, Domenighetti G, et al. Clinical classification of pulmonary hypertension. J Am Coll Cardiol. 2004;43(12 Suppl S):5S-12S.

3. Wen L, Sun ML, An P, Jiang $X$, Sun K, Zheng L, et al. Frequency of supraventricular arrhythmias in patients with idiopathic pulmonary arterial hypertension. Am J Cardiol. 2014;114(9):1420-5.

4. Olsson KM, Nickel NP, Tongers J, Hoeper MM. Atrial flutter and fibrillation in patients with pulmonary hypertension. Int J Cardiol. 2013;167(5):2300-5.

5. Ruiz-Cano MJ, Gonzalez-Mansilla A, Escribano P, Delgado J, Arribas F, Torres $J$, et al. Clinical implications of supraventricular arrhythmias in patients with severe pulmonary arterial hypertension. Int J Cardiol. 2011;146(1):105-6.

6. Tongers J, Schwerdtfeger B, Klein G, Kempf T, Schaefer A, Knapp JM, et al. Incidence and clinical relevance of supraventricular tachyarrhythmias in pulmonary hypertension. Am Heart J. 2007;153(1):127-32.

7. Daliento L, Somerville J, Presbitero P, Menti L, Brach-Prever S, Rizzoli G, et al. Eisenmenger syndrome. Factors relating to deterioration and death. Eur Heart J. 1998;19(12):1845-55.

8. Rottlaender D, Motloch LJ, Schmidt D, Reda S, Larbig R, Wolny M, et al. Clinical impact of atrial fibrillation in patients with pulmonary hypertension. PLoS One. 2012;7(3):e33902.

9. Waligora M, Tyrka A, Miszalski-Jamka T, Urbanczyk-Zawadzka M, Podolec P, Kopec G. Right atrium enlargement predicts clinically significant supraventricular arrhythmia in patients with pulmonary arterial hypertension. Heart Lung. 2018;47(3):237-42.

10. Galie N, Hoeper MM, Humbert M, Torbicki A, Vachiery JL, Barbera JA, et al. Guidelines for the diagnosis and treatment of pulmonary hypertension: the task force for the diagnosis and treatment of pulmonary hypertension of the European Society of Cardiology (ESC) and the European Respiratory Society (ERS), endorsed by the International Society of Heart and Lung Transplantation (ISHLT). Eur Heart J. 2009;30(20):2493-537.

11. Galie N, Torbicki A, Barst R, Dartevelle P, Haworth S, Higenbottam T, et al. Guidelines on diagnosis and treatment of pulmonary arterial hypertension. 
The task force on diagnosis and treatment of pulmonary arterial hypertension of the European Society of Cardiology. Eur Heart J. 2004; 25(24):2243-78.

12. Page RL, Joglar JA, Caldwell MA, Calkins H, Conti JB, Deal BJ, et al. 2015 ACC/ AHAVHRS guideline for the management of adult patients with supraventricular tachycardia: a report of the American College of Cardiology/ American Heart Association task force on clinical practice guidelines and the Heart Rhythm Society. Heart Rhythm. 2016;13(4):e136-221.

13. Showkathali R, Tayebjee MH, Grapsa J, Alzetani M, Nihoyannopoulos P, Howard LS, et al. Right atrial flutter isthmus ablation is feasible and results in acute clinical improvement in patients with persistent atrial flutter and severe pulmonary arterial hypertension. Int J Cardiol. 2011;149(2):279-80.

14. Pietra GG, Capron F, Stewart S, Leone O, Humbert M, Robbins IM, et a . Pathologic assessment of vasculopathies in pulmonary hypertension. J Am Coll Cardiol. 2004:43(12 Suppl S):25S-32S.

15. Medi C, Kalman JM, Ling LH, Teh AW, Lee G, Lee G, et al. Atrial electrical and structural remodeling associated with longstanding pulmonary hypertension and right ventricular hypertrophy in humans. J Cardiovasc Electrophysiol. 2012;23(6):614-20.

16. Folino AF, Bobbo F, Schiraldi C, Tona F, Romano S, Buja G, et al. Ventricular arrhythmias and autonomic profile in patients with primary pulmonary hypertension. Lung. 2003;181(6):321-8.

17. Schrier RW, Bansal S. Pulmonary hypertension, right ventricular failure, and kidney: different from left ventricular failure? Clin J Am Soc Nephrol. 2008; 3(5):1232-7.

18. Spach MS, Josephson ME. Initiating reentry: the role of nonuniform anisotropy in small circuits. J Cardiovasc Electrophysiol. 1994;5(2):182-209.

19. Ausma J, Wijffels M, Thone F, Wouters L, Allessie M, Borgers M. Structural changes of atrial myocardium due to sustained atrial fibrillation in the goat. Circulation. 1997;96(9):3157-63.

20. Borlaug BA, Nishimura RA, Sorajja P, Lam CS, Redfield MM. Exercise hemodynamics enhance diagnosis of early heart failure with preserved ejection fraction. Circ Heart Fail. 2010;3(5):588-95.

21. D'Alto M, Romeo E, Argiento P, Motoji Y, Correra A, Di Marco GM, et al. Clinical relevance of fluid challenge in patients evaluated for pulmonary hypertension. Chest. 2017;151(1):119-26.

22. Opitz CF, Hoeper MM, Gibbs JS, Kaemmerer H, Pepke-Zaba J, Coghlan JG, et al. Pre-capillary, combined, and post-capillary pulmonary hypertension: a pathophysiological continuum. J Am Coll Cardiol. 2016;68(4):368-78

23. Rosenkranz S, Gibbs JS, Wachter R, De Marco T, Vonk-Noordegraaf A, Vachiery JL. Left ventricular heart failure and pulmonary hypertension. Eur Heart J. 2016;37(12):942-54.

24. Wijffels MC, Kirchhof CJ, Dorland R, Allessie MA. Atrial fibrillation begets atrial fibrillation. A study in awake chronically instrumented goats. Circulation. 1995;92(7):1954-68

25. Nguyen BL, Fishbein MC, Chen LS, Chen PS, Masroor S. Histopathological substrate for chronic atrial fibrillation in humans. Heart Rhythm. 2009;6(4):454-60.

26. Chimenti C, Russo MA, Carpi A, Frustaci A. Histological substrate of human atrial fibrillation. Biomed Pharmacother. 2010;64(3):177-83.

27. Mahnkopf C, Badger TJ, Burgon NS, Daccarett M, Haslam TS, Badger CT, et al. Evaluation of the left atrial substrate in patients with lone atrial fibrillation using delayed-enhanced MRI: implications for disease progression and response to catheter ablation. Heart Rhythm. 2010;7(10):1475-81.

28. Oakes RS, Badger TJ, Kholmovski EG, Akoum N, Burgon NS, Fish EN, et al. Detection and quantification of left atrial structural remodeling with delayed-enhancement magnetic resonance imaging in patients with atrial fibrillation. Circulation. 2009;119(13):1758-67.

29. Medi C, Teh AW, Roberts-Thomson K, Morton JB, Kistler PM, Kalman JM. Right atrial remodeling is more advanced in patients with atrial flutter than with atrial fibrillation. J Cardiovasc Electrophysiol. 2012;23(10):1067-72.

\section{Publisher's Note}

Springer Nature remains neutral with regard to jurisdictional claims in published maps and institutional affiliations.

\section{Ready to submit your research? Choose BMC and benefit from:}

- fast, convenient online submission

- thorough peer review by experienced researchers in your field

- rapid publication on acceptance

- support for research data, including large and complex data types

- gold Open Access which fosters wider collaboration and increased citations

- maximum visibility for your research: over $100 \mathrm{M}$ website views per year

At BMC, research is always in progress.

Learn more biomedcentral.com/submissions 